\title{
The expression dynamics of IL-17 and Th17 response relative cytokines in the trachea and spleen of chickens after infection with Cryptosporidium baileyi
}

\author{
Guang-Hui Zhao $^{1 *+}$, Wen-Yu Cheng ${ }^{1+}$, Wan Wang ${ }^{2}$, Yan-Qing Jia ${ }^{1}$, Yan-Qin Fang ${ }^{1}$, Shuai-Zhi Du ${ }^{1}$ and San-Ke Yu ${ }^{1 *}$
}

\begin{abstract}
Background: Cryptosporidium baileyi is the dominant Cryptosporidium species in birds causing emerging health problems in the poultry industry, and is also a model to study the biology of Cryptosporidium spp.. IL-17 (also called IL-17A) is a hallmark pro-inflammatory cytokine of Th17 cells that plays an important role in several human autoimmune diseases and microbial infection disease of many animals, and it may play a role in Cryptosporidium infection.
\end{abstract}

Methods: The present study examined the mRNA level of IL-17 and Th17 response relative cytokines in the trachea and spleen of $C$. baileyi-infected chickens at different time points using real-time quantitative PCR (qPCR).

Results: All examined cytokines in the trachea were up-regulated in the infected chickens compared with the uninfected control during C. baileyi infection. Significant increased IL-17 mRNA level in the trachea was observed as early as $12 \mathrm{~h}$ post infection (pi), peaking at $24 \mathrm{~h}$ pi and $10 \mathrm{~d}$ pi, and declining thereafter. The transcription levels of IL-17 and Th17 response relative cytokines in spleen were also significantly increased at different time points during the infection.

Conclusions: IL-17 was indicated to participate in the induction of inflammation during infection of some intracellular protozoan parasites. The results in the present study suggest that IL-17 may play a role in immunity against Cryptosporidium infection, and provide basic information for determining the role of Th17 cell in Cryptosporidium infection.

Keywords: Cryptosporidium baileyi, IL-17, Chicken, Immunity

\section{Background}

Cryptosporidium spp. are monoxenous protozoan parasites that inhabit microvilli of epithelial cells in digestive, respiratory and urinary tracts of a wide range of vertebrates [1-3], causing acute, self-limiting gastroenteritis in immunocompetent individuals, and chronic or potentially fatal infections in immunocompromised subjects worldwide [4-6]. More than 240 vertebrate species have been identified with Cryptosporidium infection, including

\footnotetext{
*Correspondence: zgh083@nwsuaf.edu.cn; yusanke15@sohu.com

${ }^{\dagger}$ Equal contributors

${ }^{1}$ College of Veterinary Medicine, Northwest A\&F University, Yangling, Shaanxi Province 712100, People's Republic of China

Full list of author information is available at the end of the article
}

livestock and human. However, no effective chemotherapy or preventive interventions are available for the control of cryptosporidiosis [7]. Considering that the infection status and severity of cryptosporidiosis are closely related to immunity of individuals, the knowledge of the host immune mechanisms against Cryptosporidium infection is essential for controlling this disease.

Previous studies have suggested that host resistance against C. parvum infection is established through both innate and adaptive immune responses [8,9]. Intestinal epithelial cells (IECs), natural killer (NK) cells, phagocytes, dendritic cells (DCs), interferon- $\gamma$, nitric oxide and the complement system play some protective roles at the beginning of infection [9]. Evidence from studies on 
C. parvum infections of murine, bovine, and humans suggested an important role for $\mathrm{T}$ cell-derived cytokines in the recovery from Cryptosporidium infection [9-12]. The importance of $\mathrm{CD}_{4}^{+} \mathrm{T}$ cells in immunity to Cryptosporidium infection has been demonstrated in murine infection models of C. parvum $[9,13,14]$. Subsequent findings demonstrated that both Th1 and Th2 cells have roles in controlling $C$. parvum infection, and there is a strong Th1 response during early infection but the later maturation of a more balanced response with a Th2 component may facilitate parasite removal $[7,14]$. However, an infection study using a knock out mouse model revealed that hosts lacking IFN- $\gamma$ and IL-4 could still finally eliminate the parasites [15].

Recently, a new T-cell subset, largely produced by activated $\mathrm{CD}^{+}{ }^{+} \mathrm{T}$ cells distinct from Th1 or Th2 cells, designated as Th17, was identified [16,17]. A hallmark of this Th-cell subset is the production of IL-17A (also called IL-17), a pro-inflammatory cytokine that plays an important role in several diseases as well as Th17 cells [18]. Factors that promote Th17 cell differentiation and/or expansion are transforming growth factor (TGF)- $\beta$, IL-6 and IL-23 $[17,19]$. The differentiation is regulated by the transcription factor signal transducer and activator of transcription 3 (STAT-3), retinoic acid receptor-related orphan receptor- $\gamma \tau(\mathrm{ROR} \gamma \tau)$ and aryl hydrocarbon receptor [20]. IL-17 promotes inflammation by enhancing production of cytokines such as IL- $1 \beta$, TNF- $\alpha$, IL- 6 and receptor activation of nuclear factor- $\mathrm{k} B$ ligand (RANKL) $[21,22]$. Th17 cells are thought to increase inflammation by recruiting cells, particularly neutrophils, to the peripheral tissues for pathogen clearance [23].

Although IL-17 has a role in the host's protection against fungal and bacterial infection, the roles of IL-17 in host defense against intracellular protozoan parasites remain to be fully elucidated [24-26]. Several infection studies with various protozoal species demonstrated that Th17 cells may mediate the host defense against Trypanosoma cruzi [27], Pneumocystis carinii [28] and Toxoplasma gondii [29]. However, controversial results have been shown in human cutaneous leishmaniasis [30], T. gondii infection [31] and Eimeria tenella infection in chicken [32], which suggests that IL-17 contributes to the pathology of these infections.

Cryptosporidium baileyi, the dominant species and more frequently associated with high morbidity and mortality $[33,34]$ in birds, mainly parasitizes the respiratory tract (larynx, trachea, primary and secondary bronchi and air sacs), bursa of Fabricius and cloaca of chickens, turkeys and ducks, and causes respiratory disorders, clinically characterized by rales, coughing, dyspnoea, and sneezing [33,35,36]. Ditrich et al. [37] also detected C. baileyi in the stool of an immunodeficient man, suggesting the zoonotic fact of this species. Considering the morphological and biological features and large oocyst production, $C$. baileyi has been suggested as a model for characterization of cryptosporidia [38]. Since C. baileyi represents a kind of respiratory intracellular parasite and can be an ideal infection model for study of respiratory infection, the expression dynamics of IL-17 and Th17 response relative cytokines in the trachea and spleen of chickens after infection with $C$. baileyi were studied. The results will have important implications for determining the role of IL-17 and Th17 cell in Cryptosporidium infection.

\section{Methods}

\section{Ethics statement}

The performance of this study was strictly according to the recommendations of the Guide for the Care and Use of Laboratory Animals of the Ministry of Health, China, and our protocol was reviewed and approved by the Research Ethics Committee of Northwest A\&F University.

\section{Chickens}

One-day-old Arbor Acre (AA) broiler cockerels purchased from the Youming Broiler Hatchery (Shaanxi, China) were reared in a coccidia-free laboratory, housed in wire cages, and given free access to feed and water and constant light during the entire experimental period. Chickens were randomly assigned to four groups of 10 birds per group ( 5 birds per cage). All animal experiments were carried out in compliance with current Chinese ethical legislation.

\section{Parasites}

The wild-type strain of C. baileyi was originally isolated from a natural infected chick and identified using microscopic and molecular analyses. Oocysts were maintained by passage every two months in susceptible chickens at the College of Veterinary Medicine, Northwest A\&F University, China.

\section{Parasite infection and measurements of fecal oocyst shedding}

A total of 20 4-day-old chickens were each inoculated orally with a single dose of $1 \times 10^{5} \mathrm{C}$. baileyi oocysts (in $100 \mu \mathrm{L}$ of PBS). Meanwhile, a total of 20 uninfected agematched chickens served as control group and were given $100 \mu \mathrm{L}$ PBS. For the determination of fecal oocyst shedding, birds (10 per group) were placed in oocyst collection cages and fecal samples were collected daily following inoculation. Numbers of oocyst per gram (OPG) of feces per group sample were determined using a hemacytometer according to the following formula: OPG/group $=\left[(\right.$ oocyst count $\left./ 4) \times 10^{4} \times 5 \times 5\right] /$ weight of fecal sample. 


\section{RNA extraction and cDNA synthesis}

Five chickens from control and infected groups were euthanized by cervical dislocation at $3 \mathrm{~h}, 6 \mathrm{~h}, 12 \mathrm{~h}, 24 \mathrm{~h}$, $48 \mathrm{~h}, 96 \mathrm{~h}, 7 \mathrm{~d}, 10 \mathrm{~d}, 13 \mathrm{~d}$ and $16 \mathrm{~d}$ post infection (pi), then spleen and trachea were isolated. Total RNA was isolated from $<100 \mathrm{mg}$ of the tissues previously snap-frozen in liquid nitrogen. The RNA samples were extracted using TRIzol agent (Invitrogen) following the manufacturer's instructions, with the RNA purity and concentration determined by spectrophotometric absorbance at 260 and $280 \mathrm{~nm}$. The RNA sample $(0.5 \mu \mathrm{g})$ was reversely transcribed into cDNA using PrimeScript ${ }^{\mathrm{TM}} \mathrm{RT}$ reagent Kit (TaKaRa, DALIAN).

\section{Quantitative real-time RT-PCR}

Quantitative RT-PCR oligonucleotide primers for chicken cytokines and $\beta$-actin control are described by Zhang et al. [32]. qPCR reactions of the genes were performed on an iQ5 Real-Time PCR Detection System (Bio-Rad, USA) using UltraSYBR Mixture (CWBIO, China). Amplification and detection of specific products were performed with the following conditions: one cycle of $95^{\circ} \mathrm{C}$ for $3 \mathrm{~min}$, followed by 40 cycles of $95^{\circ} \mathrm{C}$ for $15 \mathrm{~s}, 56^{\circ} \mathrm{C}$ for $30 \mathrm{~s}$. Relative gene expression data were analyzed using the $2^{-\Delta \Delta C t}$ method [39].

\section{Statistical analysis}

The data was analyzed using SPSS software (SPSS 18.0 for Windows; SPSS, Chicago, IL, USA), with one-way analysis of variance followed by the Duncan's multiple range test. All data were expressed as the mean \pm SD of 5 chickens per group with three replicates per sample. Differences between groups were considered statistically significant at $\mathrm{P}<0.05$.

\section{Results and discussion}

To determine the law of oocyst shedding by infected chickens, fecal samples were collected and examined daily post infection (pi) by oocyst counting according to the method described by Gao et al. [40]. Oocyst shedding in the pooled fecal samples was firstly observed on day 4 pi and the highest levels of oocyst shedding occurred on day $10 \mathrm{pi}, 12 \mathrm{pi}$ and $14 \mathrm{pi}$, peaking at day 10 pi and declining thereafter (Additional file 1). Clinical signs of respiratory disease, consisting of rales, sneezing, and dyspnea were observed in all inoculated birds from day 10 pi to 21 pi. Two deaths occurred in the infected group at day $10 \mathrm{pi}$ and $12 \mathrm{pi}$, respectively.

The expression of IL-17 (Figure 1) and Th17 response relative cytokines (IL-1 $\beta$, IL- 6 and TGF- $\beta$, Figure 2) and transcription factor (STAT3) were detected in the trachea during the infection of $C$. baileyi. All these cytokines in the trachea were up-regulated in the infected chickens compared with the uninfected control during

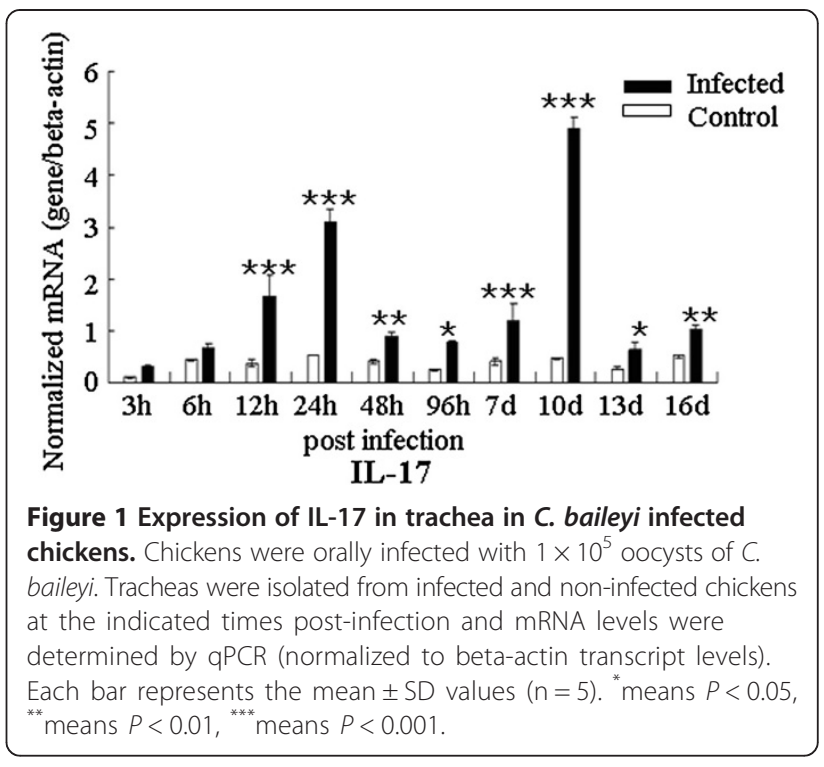

the C. baileyi infection. Significant increase in IL-17 mRNA expression was observed as early as $12 \mathrm{~h}$ pi, peaking at $24 \mathrm{~h}$ pi and $10 \mathrm{~d} \mathrm{pi}$, and declining thereafter. The expression level of STAT3, one of the key transcription factors for the polarization of Th17 cells, was also robustly up-regulated as early as $12 \mathrm{~h}$ pi, peaking at $10 \mathrm{~d}$ pi. For the expression of IL- 6 and TGF- $\beta$, the early peaks were observed at $12 \mathrm{~h}$ pi and $6 \mathrm{~h}$ pi, respectively, while both of two cytokines have a peak at $10 \mathrm{~d}$ pi later. Interestingly, we observed significantly higher mRNA levels of all cytokines (IL-1 $\beta$, IL-6, IL-17, TGF- $\beta$ and STAT3) at $10 \mathrm{~d} \mathrm{pi}$, which is consistent with the oocyst shedding pattern (Additional file 1) in which the peak level of oocyst shedding was observed on day 10 pi.

In addition, we also examined expression of the IL-17 and Th17 response relative cytokines in the transcription level in spleen during the infection (Figures 3 and 4). The expression levels of IL-1 $\beta$ and IL- 6 were up-regulated at $12 \mathrm{~h}$ pi and $24 \mathrm{~h}$ pi during the early phase of the infection, and then they had a peak at $10 \mathrm{~d}$ pi and $96 \mathrm{~h}$ pi, respectively (Figure 3). The up-regulation of IL-17 mRNA level in infected chickens was observed at $48 \mathrm{~h} \mathrm{pi,} 96 \mathrm{~h}$ pi, $10 \mathrm{~d}$ pi and $13 \mathrm{~d}$ pi compared with that in uninfected controls (Figure 4). For the TGF- $\beta$, the mRNA level was robustly up-regulated at $24 \mathrm{~h}$ pi and moderately upregulated $96 \mathrm{~h}$ pi and $7 \mathrm{~d}$ pi. However, unique to all the molecules examined in spleen, STAT3 transcription level was only significantly increased at $96 \mathrm{~h}$ pi during the infection.

Although IL-17 is known to participate in the induction of inflammation during infection of some intracellular protozoan parasites, such as Toxoplasma gondii [29], Leishmania amazonensis [41], Trypanosoma cruzi [27,42] and Eimeria spp. $[32,43,44]$, the pathogenic or protective roles of IL-17 in infection by other intracellular protozoan 


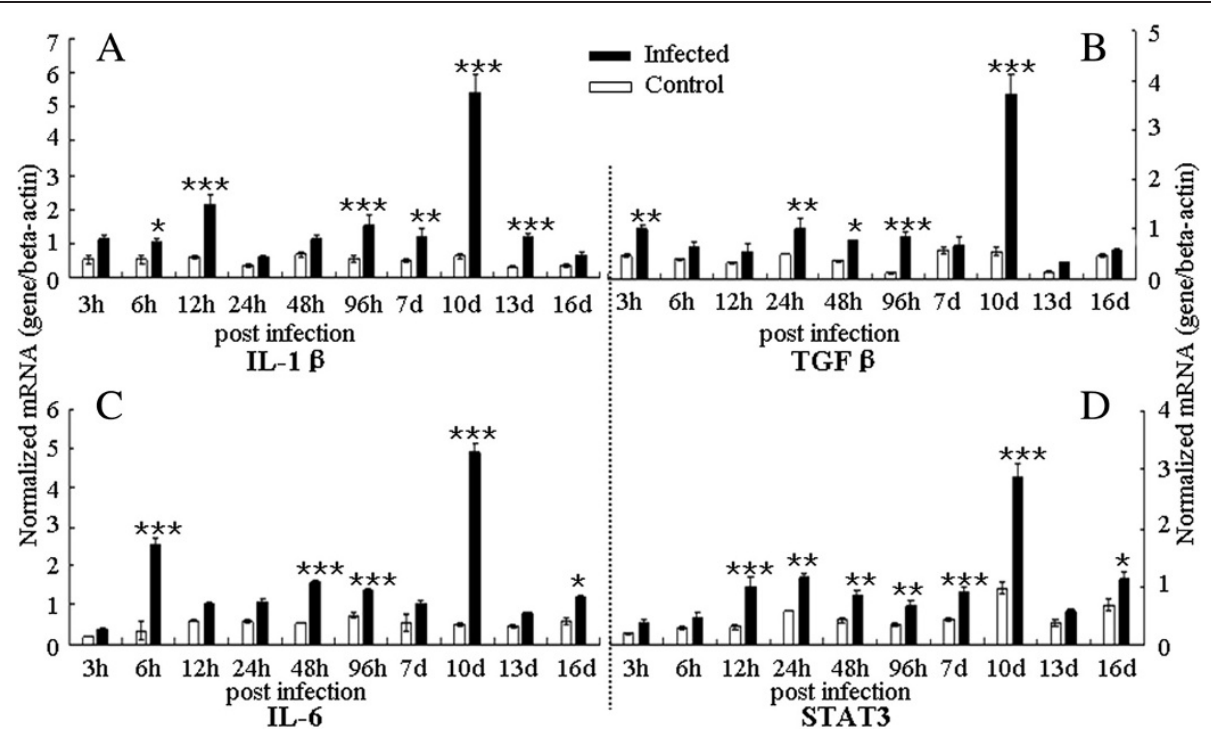

Figure 2 Expression of Th17 response relative cytokines in the trachea in C. baileyi infected chickens. Chickens were orally infected with $1 \times 10^{5}$ oocysts of $C$. baileyi. Tracheas were isolated from infected and non-infected chickens at the indicated times post-infection and mRNA levels were determined by qPCR (normalized to beta-actin transcript levels). (A) IL-1 $\beta$; (B) TGF- $\beta$; (C) IL-6; (D) STAT3; Each bar represents the mean \pm SD values $(\mathrm{n}=5)$. ${ }^{*}$ means $P<0.05,{ }^{* *}$ means $P<0.01,{ }^{* * *}$ means $P<0.001$.

parasites are not well understood. In this study, we studied expression dynamics of IL-17 and Th17 relative cytokines at various time-points after $C$. baileyi infection. The mRNA level of IL-17 in trachea was up-regulated from $12 \mathrm{~h}$ pi, with peaks at $12 \mathrm{~h}, 24 \mathrm{~h}$, and $10 \mathrm{~d}$ pi, while the mRNA level of IL-17 in spleen was with peaks at $48 \mathrm{~h}$ pi and $10 \mathrm{~d}$ pi. These results suggested that the IL-17 may participate in the innate and adaptive immune responses against $C$. baileyi infection.

Biological functions of IL-17 and its roles in disease have been intensively reviewed [45]. IL-17 has an important role in maintaining the mucosal barrier integrity, and it enhances the synthesis of the tight junction protein claudin to strengthen the connections between

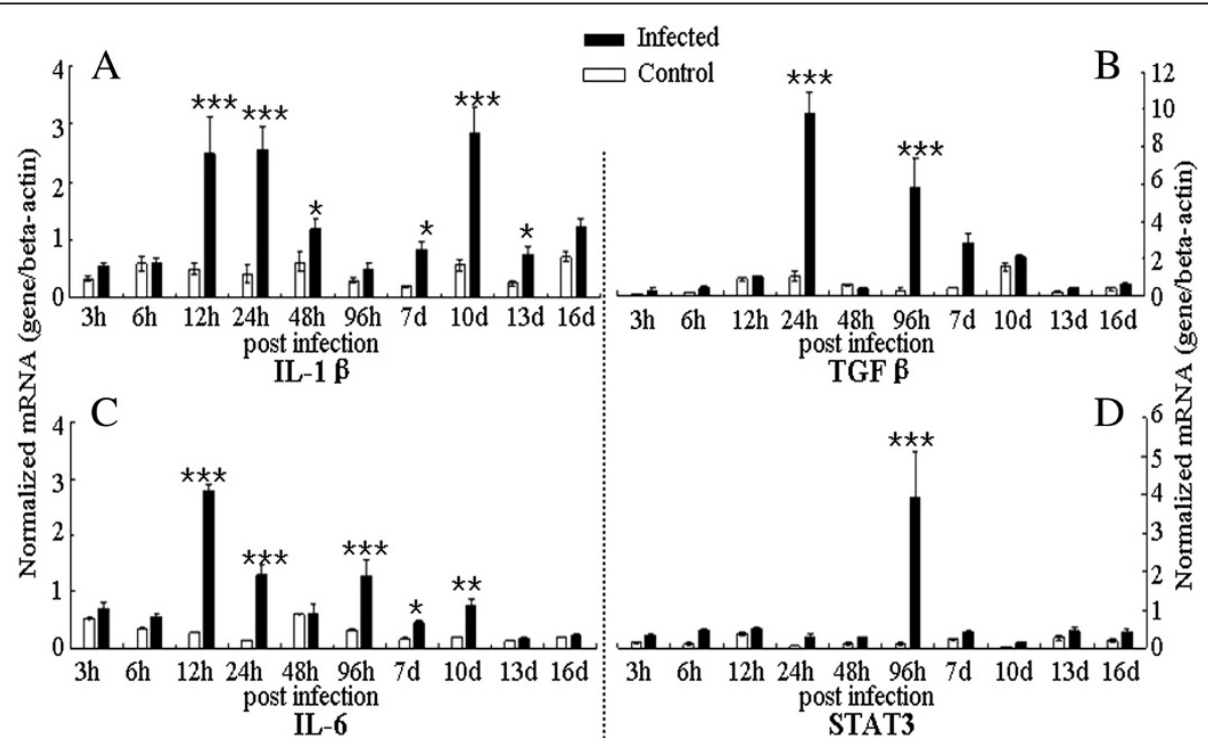

Figure 3 Expression of Th17 response relative cytokines in spleen in C. baileyi infected chickens. Chickens were orally infected with $1 \times 10^{5}$ oocysts of $C$. baileyi. Spleens were isolated from infected and non-infected chickens at the indicated times post-infection and mRNA levels were determined by qPCR (normalized to beta-actin transcript levels). (A) IL-1 $\beta$; (B) TGF- $\beta$; (C) IL-6; (D) STAT3; Each bar represents the mean \pm SD values $(\mathrm{n}=5)$. ${ }^{*}$ means $P<0.05,{ }^{* *}$ means $P<0.01,{ }^{* * *}$ means $P<0.001$. 


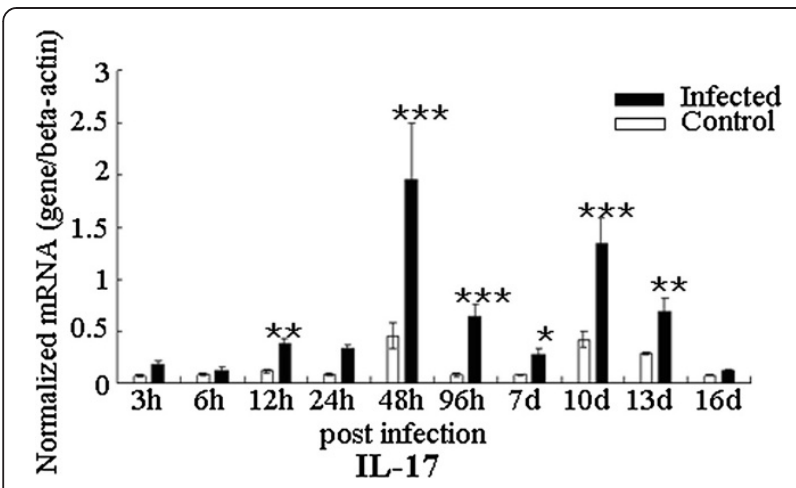

Figure 4 Expression of IL-17 in spleen in C. baileyi infected chickens. Chickens were orally infected with $1 \times 10^{5}$ oocysts of c. baileyi. Spleens were isolated from infected and non-infected chickens at the indicated times post-infection and mRNA levels were determined by aPCR (normalized to beta-actin transcript levels). Each bar represents the mean \pm SD values $(n=5)$. ${ }^{*}$ means $P<0.05,{ }^{* *}$ means $P<0.01$, ${ }^{* * *}$ means $P<0.001$.

epithelial cells [46]. Zhang et al. [32] reported that IL-17 might induce immunopathology during Eimeria tenella infection in chickens. In their study, IL-17 has a robust up-regulation at $6 \mathrm{~h}$ pi during the early infection, but the neutralized IL-17 resulted in significantly enhanced weight gains, reduced fecal oocyst shedding, and reduced cecal lesion scores compared with control [32]. However, there were also some studies suggesting that Th17 response played a central role in regulating parasite-induced diseases $[42,47,48]$. C. baileyi is able to establish itself in the mucosal epithelium of a wide variety of organs [35], with the trachea as the most common parasitic site to present inflammation and clinical signs. In the present study, mild clinical symptoms were firstly observed at $8 \mathrm{~d}$ pi in the infected group, and affected individuals presented dyspnoea, depression and loose stools. At $10 \mathrm{~d}$ pi, all chickens were seen with respiratory symptoms. Dead chickens were also found in the infected group at day $10 \mathrm{pi}$ and $12 \mathrm{pi}$. Autopsy of dead chickens revealed inflammation and excessive mucus in tracheas. qPCR analysis showed that expression of IL-17 and Th17 response relative cytokines (IL$1 \beta$, IL-6 and TGF- $\beta$ ) were up-regulated in tracheas during the course of infection, with the highest levels at day 10 pi. These results suggested that IL-17 may be one of the causes in inducing pathogenic lesions in Cryptosporidium infection.

\section{Conclusions}

The present study examined the expression dynamics of IL-17 and Th17 response relative to cytokines after infection with C. baileyi. During oral experimental C. baileyi infection, IL-17 and related cytokine expression were up-regulated in trachea and spleen of chickens after infection, with the highest levels in tracheas at day 10 pi when the peak oocyst shedding and pathogenic lesions were observed, which suggested that IL-17 may play a role in immunity against Cryptosporidium infection. These results would provide basic information for studying pathogenic mechanisms of Cryptosporidium spp. and immunity of host against Cryptosporidium infections. However, due to few commercial monoclonal antibodies being available for IL-17 and Th17 responses relative cytokines in chickens, immunological methods, such as ELISA and immunohistochemical, are difficult to develop and use. Therefore, to further confirm the role of Th17 cells in immunity in cryptosporidiosis, we will develop monoclonal antibodies for IL-17 of chicken, and study the expression of these cytokines in protein level and the number of Th17 cells during infection in the future.

\section{Additional file}

Additional file 1: The oocyst shedding patterns of chickens after inoculation with $1 \times 10^{5}$ C. baileyi oocysts.

\section{Competing interests}

The authors declare that they have no competing interests.

\section{Authors' contributions}

GHZ and SKY conceived and designed the study, and critically revised the manuscript. WYC, WW, YQJ, SZD and YQF performed the experiments, analyzed the data and drafted the manuscript. All authors read and approved the final manuscript.

\section{Acknowledgements}

This work was supported, in part, by the National Natural Science Foundation of China (Grant No. 31101805), the Program for New Century Excellent Talents in University (NCET-13-0489), the Fund for Basic Scientific Research (Grant No. ZD2012010), and the Open Funds of the State Key Laboratory of Veterinary Etiological Biology, Lanzhou Veterinary Research Institute, Chinese Academy of Agricultural Sciences (Grant No. SKLVEB2013KFKT007).

\section{Author details}

${ }^{1}$ College of Veterinary Medicine, Northwest A\&F University, Yangling, Shaanxi Province 712100, People's Republic of China. ${ }^{2}$ College of Life Sciences, Northwest A\&F University, Yangling, Shaanxi Province 712100, People's Republic of China.

Received: 19 December 2013 Accepted: 28 April 2014 Published: 6 May 2014

\section{References}

1. Bouzid M, Hunter PR, Chalmers RM, Tyler KM: Cryptosporidium pathogenicity and virulence. Clin Microbiol Rev 2013, 26:115-134.

2. Koh W, Clode PL, Monis P, Thompson RC: Multiplication of the waterborne pathogen Cryptosporidium parvum in an aquatic biofilm system. Parasit Vectors 2013, 6:270.

3. Zhao G, He S, Chen L, Shi N, Bai Y, Zhu XQ: Teaching human parasitology in China. Parasit Vectors 2012, 5:77.

4. Tian L, Chen J, Wang T, Cheng G, Steinmann P, Wang F, Cai Y, Yin X, Guo J, Zhou L, Zhou X: Co-infection of HIV and intestinal parasites in rural area of China. Parasit Vectors 2012, 5:36-42.

5. Abeywardena H, Jex AR, Koehler AV, Rajapakse RJ, Udayawarna K, Haydon SR, Stevens MA, Gasser RB: First molecular characterization of Cryptosporidium 
and Giardia from bovines (Bos Taurus and Bubalus bubalis) in Sri Lanka: unexpected absence of $C$. parvum from pre-weaned calves. Parasit Vectors 2014, 7:75.

6. Chen JH, Wang H, Chen JX, Bergquist R, Tanner M, Utzinger J, Zhou XN: Frontiers of parasitology research in the People's Republic of China: infection, diagnosis, protection and surveillance. Parasit Vectors 2012, 5:221

7. Tessema TS, Schwamb B, Lochner M, Forster I, Jakobi V, Petry F: Dynamics of gut mucosal and systemic Th1/Th2 cytokine responses in interferon-gamma and interleukin-12p40 knock out mice during primary and challenge Cryptosporidium parvum infection. Immunobiol 2009, 214:454-466.

8. Barakat FM, McDonald V, Di Santo JP, Korbel DS: Roles for NK cells and an NK cell-independent source of intestinal gamma interferon for innate immunity to Cryptosporidium parvum infection. Infect Immun 2009, 77:5044-5049.

9. Petry F, Jakobi V, Tessema TS: Host immune response to Cryptosporidium parvum infection. Exp Parasitol 2010, 126:304-309.

10. Riggs MW: Recent advances in cryptosporidiosis: the immune response. Microbes Infect 2002, 4:1067-1080.

11. MCNair NN, Mead JR: CD4 ${ }^{+}$effector and memory cell populations protect against Cryptosporidium parvum infection. Microbes Infect 2013, 15:599-606.

12. Borad A, Ward H: Human immune responses in cryptosporidiosis. Future Microbiol 2010, 5:507-519.

13. Aguirre SA, Mason PH, Perryman LE: Susceptibility of major histocompatibility complex (MHC) class I- and MHC class II-deficient mice to Cryptosporidium parvum infection. Infect Immun 1994 62:697-699.

14. McDonald V: Host cell-mediated responses to infection with Cryptosporidium. Parasite Immunol 2000, 22:597-604

15. Ehigiator HN, Romagnoli P, Borgelt K, Fernandez M, McNair N, Secor WE, Mead JR: Mucosal cytokine and antigen-specific responses to Cryptosporidium parvum in IL-12p40 KO mice. Parasite Immunol 2005 27:17-28.

16. Harrington LE, Hatton RD, Mangan PR, Turner H, Murphy TL, Murphy KM Weaver $\mathrm{CT}$ : Interleukin 17-producing $\mathrm{CD}^{+}$effector T cells develop via a lineage distinct from the Thelper type 1 and 2 lineages. Nat Immunol 2005, 6:1123-1132

17. Peters A, Yosef $\mathrm{N}$ : Understanding Th17 cells through systematic genomic analyses. Curr Opin Immunol 2014, 28C:42-48.

18. Tesmer LA, Lundy SK, Sarkar S, Fox DA: Th17 cells in human disease. Immunol Rev 2008, 223:87-113.

19. Heinze DM, Wikel SK, Thangamani S, Alarcon-Chaidez FJ: Transcriptional profiling of the murine cutaneous response during initial and subsequent infestations with Ixodes scapularis nymphs. Parasit Vectors 2012, 5:26.

20. Gaffen SL: Structure and signalling in the IL-17 receptor family. Nat Rev Immunol 2009, 9:556-567.

21. Hwang SY, Kim JY, Kim KW, Park MK, Moon Y, Kim WU, Kim HY: IL-17 induces production of IL- 6 and IL-8 in rheumatoid arthritis synovial fibroblasts via NF-kappaB- and PI3-kinase/Akt-dependent pathways. Arthritis Res Ther 2008, 6:R120-R128.

22. Bystrom J, Al-Adhoubi N, Al-Bogami M, Jawad AS, Mageed RA: Th17 lymphocytes in respiratory syncytial virus infection. Viruses 2013, 5:777-791.

23. Roark $\mathrm{CL}$, Simonian $\mathrm{PL}$, Fontenot $\mathrm{AP}$, Born WK, O'Brien RL: Gammadelta T cells: an important source of IL-17. Curr Opin Immunol 2008, 20:353-357.

24. Wang F, Xu J, Liao Y, Wang Y, Liu C, Zhu X, Chen ZK, Sun Z: Tim-3 ligand galectin- 9 reduces IL-17 level and accelerates Klebsiella pneumoniae infection. Cell Immunol 2011, 269:22-28.

25. Ferreira MC, Whibley N, Mamo AJ, Siebenlist U, Chan YR, Gaffen SL: Interleukin-17-induced protein lipocalin 2 is dispensable for immunity to oral candidiasis. Infect Immun 2014, 82:1030-1035.

26. Liu J, Qu H, Li Q, Ye L, Ma G, Wan H: The responses of $\gamma \delta$ T-cells against acute Pseudomonas aeruginosa pulmonary infection in mice via interleukin-17. Pathog Dis 2013, 68:44-51.

27. Miyazaki Y, Hamano S, Wang S, Shimanoe Y, Iwakura Y, Yoshida H: IL-17 is necessary for host protection against acute-phase Trypanosoma cruzi infection. J Immunol 2010, 185:1150-1157.
28. Rudner XL, Happel KI, Young EA, Shellito JE: Interleukin-23 (IL-23)-IL-17 cytokine axis in murine Pneumocystis carinii infection. Infect Immun 2007, 75:3055-3061.

29. Kelly MN, Kolls JK, Happel K, Schwartzman JD, Schwarzenberger P, Combe C, Moretto M, Khan IA: Interleukin-17/interleukin-17 receptor-mediated signaling is important for generation of an optimal polymorphonuclear response against Toxoplasma gondii infection. Infect Immun 2005, 73:617-621.

30. Gonzalez-Lombana C, Gimblet C, Bacellar O, Oliveira WW, Passos S, Carvalho LP, Goldschmidt M, Carvalho EM, Scott P: IL-17 mediates immunopathology in the absence of IL-10 following Leishmania major infection. PLOS Pathog 2013, 9:e1003243.

31. Dutra MS, Béla SR, Peixoto-Rangel AL, Fakiola M, Cruz AG, Gazzinelli A, Quites HF, Bahia-Oliveira LM, Peixe RG, Campos WR, Higino-Rocha AC, Miller NE, Blackwell JM, Antonelli LR, Gazzinelli RT: Association of a NOD2 gene polymorphism and T-helper 17 cells with presumed ocular toxoplasmosis. J Infect Dis 2013, 207:152-163.

32. Zhang L, Liu R, Song M, Hu Y, Pan B, Cai J, Wang M: Eimeria tenella: interleukin 17 contributes to host immunopathology in the gut during experimental infection. Exp Parasitol 2013, 133:121-130.

33. Ryan U: Cryptosporidium in birds, fish and amphibians. Exp Parasito/ 2010 124:113-120.

34. Wang R, Jian F, Sun Y, Hu Q, Zhu J, Wang F, Ning C, Zhang L, Xiao L: Large-scale survey of Cryptosporidium spp. in chickens and Pekin ducks (Anas platyrhynchos) in Henan, China: prevalence and molecular characterization. Avian Pathol 2010, 39:447-451.

35. Current WL, Upton SJ, Haynes TB: The life cycle of Cryptosporidium baileyi n. sp. (Apicomplexa, Cryptosporidiidae) infecting chickens. J Protozool 1986, 33:289-296.

36. Molina-López RA, Ramis A, Martin-Vázquez S, Gómez-Couso H, Ares-Mazás E, Cacciò SM, Leiva M, Darwich L: Cryptosporidium baileyi infection associated with an outbreak of ocular and respiratory disease in otus owls (Otus scops) in a rehabilitation centre. Avian Pathol 2010, 39:171-176.

37. Ditrich O, Palkovic L, Stĕrba J, Prokopic J, Loudová J, Giboda M: The first finding of Cryptosporidium baileyi in man. Parasitol Res 1991, 77:44-47

38. Egyed Z, Sréter T, Széll Z, Beszteri B, Dobos-Kovács M, Márialigeti K, Cornelissen AW, Varga I: Polyphasic typing of Cryptosporidium baileyi: a suggested model for characterization of cryptosporidia. J Parasitol 2002, 88:237-243.

39. Livak KJ, Schmittgen TD: Analysis of relative gene expression data using real-time quantitative $P C R$ and the 2(-Delta Delta $C(T)$ ) Method. Methods 2001, 25:402-408.

40. Gao GQ, Qi M, Wang Y, Xu LN, Wang RJ, Huang L, Zhang SM, Jian FC, Ning CS, Zhang LX: Pathogenicity of Cryptosporidium baileyi isolates derived from different poultry hosts in quail. Acta Vet Zootec $\operatorname{Sin} 2010$, 41:200-207 (in Chinese)

41. Sousa LM, Carneiro MB, Resende ME, Martins LS, Dos Santos LM, Vaz LG, Mello PS, Mosser DM, Oliveira MA, Vieira LQ: Neutrophils have a protective role during early stages of Leishmania amazonensis infection in BALB/C mice. Parasite Immunol 2014, 36:13-31.

42. da Matta Guedes PM, Gutierrez FR, Maia FL, Milanezi CM, Silva GK, Pavanelli WR, Silva JS: IL-17 produced during Trypanosoma cruzi infection plays a central role in regulating parasite-induced myocarditis. PLoS Negl Trop Dis 2010, 4:e604.

43. Hong YH, Lillehoj HS, Lee SH, Dalloul RA, Lillehoj EP: Analysis of chicken cytokine and chemokine gene expression following Eimeria acervulina and Eimeria tenella infections. Vet Immunol Immunopathol 2006, 114:209-223.

44. Hong YH, Lillehoj HS, Lillehoj EP, Lee SH: Changes in immune-related gene expression and intestinal lymphocyte subpopulations following Eimeria maxima infection of chickens. Vet Immunol Immunopathol 2006 114:259-272

45. Ouyang $W$, Kolls JK, Zheng Y: The biological functions of $T$ helper 17 cell effector cytokines in inflammation. Immunity 2008, 28:454-467

46. Pappu R, Rutz S, Ouyang W: Regulation of epithelial immunity by IL-17 family cytokines. Trends Immunol 2012, 33:343-349.

47. Guiton R, Vasseur V, Charron S, Arias MT, Van Langendonck N, Buzoni-Gatel $D$, Ryffel $B$, Dimier-Poisson I: Interleukin 17 receptor signaling is 
deleterious during Toxoplasma gondii infection in susceptible BL6 mice. $J$ Infect Dis 2010, 202:427-435.

48. Katara GK, Raj A, Kumar R, Avishek K, Kaushal H, Ansari NA, Bumb RA, Salotra $P$ : Analysis of localized immune responses reveals presence of Th17 and Treg cells in cutaneous leishmaniasis due to Leishmania tropica. BMC Immunol 2013, 14:52.

doi:10.1186/1756-3305-7-212

Cite this article as: Zhao et al:: The expression dynamics of IL-17 and

Th17 response relative cytokines in the trachea and spleen of chickens

after infection with Cryptosporidium baileyi. Parasites \& Vectors 2014 7:212.

\section{Submit your next manuscript to BioMed Central and take full advantage of:}

- Convenient online submission

- Thorough peer review

- No space constraints or color figure charges

- Immediate publication on acceptance

- Inclusion in PubMed, CAS, Scopus and Google Scholar

- Research which is freely available for redistribution 